\title{
TETRAPOD POSTURAL SHIFT ESTIMATED FROM PERMIAN AND TRIASSIC TRACKWAYS
}

\author{
by TAI KUBO* and MICHAEL J. BENTON† \\ ${ }^{\star}$ Department of Earth and Planetary Science, University of Tokyo, 7-3-1, Hongo, Bunkyouku, Tokyo 113-0033, Japan; e-mail taikubo@eps.s.u-tokyo.ac.jp \\ $\uparrow$ Department of Earth Sciences, University of Bristol, Bristol BS8 1RJ, UK; e-mail mike.benton@bris.ac.uk \\ Typescript received 19 February 2008; accepted in revised form 6 November 2008
}

\begin{abstract}
The end-Permian mass extinction, 252 million years (myr) ago, marks a major shift in the posture of tetrapods. Before the mass extinction, terrestrial tetrapods were sprawlers, walking with their limbs extended to the sides; after the event, most large tetrapods had adopted an erect posture with their limbs tucked under the body. This shift had been suspected from the study of skeletal fossils, but had been documented as a long process that occupied some 15-20 myr of the Triassic. This study reads posture directly from fossil tracks, using a clear criterion for sprawling vs
\end{abstract}

erect posture. The track record is richer than the skeletal record, especially for the Early and Middle Triassic intervals, the critical 20 myr during which period the postural shift occurred. The shift to erect posture was completed within the 6 myr of the Early Triassic and affected both lineages of medium to large tetrapods of the time, the diapsids and synapsids.

Key words: Tetrapods, limb posture, trackway, Permian, Triassic.
L I M B postures of tetrapods vary from sprawling to erect, based on the degree of adduction/abduction of limbs. Birds and cursorial mammals have erect limb posture, where the limbs are held under the body and move in a parasagittal plane (parallel to the sagittal plane, which divides the body into left and right halves). On the other hand, a sprawling limb posture is seen today in lizards and salamanders, where the proximal limb segments are highly abducted and swing largely in a horizontal plane (Blob 2000).

An erect limb posture has advantages over a sprawling limb posture, especially for large animals. Stresses over the knee and elbow joints are reduced when the limbs are held vertical. Also, a sprawling limb posture may disturb respiration during locomotion, and as a consequence erect forms have more endurance than sprawlers (Carrier 1987).

Postural categories among tetrapods are continuous and so cannot simply be divided into 'sprawling' and 'erect'. To replace these artificial categories, limb abduction angle, the smallest three-dimensional angle between the femoral axis and the parasagittal plane, has been proposed to describe limb posture quantitatively (Gatesy 1991). For instance, within the 'erect' category, some lightweight noncursorial mammals, such as echidnas, opossums, weasels and their relatives, and rodents, move their limbs in a partially sprawling mode, where the femur is abducted 25-50 degrees from the parasagittal plane, whereas large-bodied cursorial mammals, such as cats and dogs, have a fully parasagittal stance, in which the femur is abducted <15 degrees (Jenkins 1971; Jenkins and Camazine 1977). Although the depression angle, a three dimensional angle between the femur and horizontal plane, was measured for several lizards (i.e. Jayne and Irschick 1999; Spezzano and Jayne 2004), femoral abduction angle has not been measured in kinematic studies of modern 'sprawlers', such as lizards and salamanders. Therefore, conventional terms describing tetrapod posture are used in this study; newts, salamanders, turtles, and lizards are 'sprawlers', crocodilians are 'semierect', birds and mammals are 'erect'. Among mammals, felids and canids are 'fully erect' or 'cursorial', whereas didelphids, murids and mustelids are 'noncursorial'. We did not include other mammals in these two categories, because only members of these families have had their femoral abduction angles published (Jenkins 1971; Jenkins and Camazine 1977).

From skeletal fossils, it has been assumed that therapsids, a clade of synapsids that includes mammals and their immediate ancestors, had a semierect or dual posture in the Middle or Late Permian that evolved into a fully erect 'mammalian' posture in the Late Triassic (Kemp 1982; Blob 2001; Ray and Chinsamy 2003). An erect posture emerged independently through the Triassic among diapsids too, specifically archosaurs, the group that includes crocodilians, dinosaurs and birds (Bonaparte 1984; Parrish 1987; Hutchinson 2006). The terms 'Archosauria' 
and 'archosaur' are used here in the broad, traditional sense to refer to the clade of proterosuchids and birds and everything else in between. The postural transition among archosaurs from sprawling to erect has been inferred as a multistage process (Charig 1972). The Early Triassic archosaurs such as Proterosuchus and Erythrosuchus have generally been classified as sprawlers, the Early and Middle Triassic forms Euparkeria and Proterochampsa as semierect, and the Middle and Late Triassic forms such as Peteinosaurus (pterosaur), Marasuchus (dinosauromorph), Eoraptor (dinosaur) and Saltoposuchus (crocodilomorph) as erect (Charig 1972; Bonaparte 1984; Parrish 1987). An erect posture, according to these studies, probably arose among archosaurs towards the end of the Middle Triassic. Nevertheless, the pattern of radiation of erect forms in tetrapod faunas remains largely ambiguous because body fossils are rare, and especially those that are complete enough for their posture to be diagnosed.

Sprawling and erect stance may be determined directly from tracks by assessing the ratio of stride length to trackway width. This is readily indicated by pace angulation, the angle formed by three continuous front or hind footprints (Text-fig. 1A), a measurement proposed previously (Peabody 1959), but not rigorously tested on living animals. The assumption is that an erect animal using a parasagittal stance shows high pace angulation, while a sprawler shows low pace angulation, as the more adducted limb can reduce the trackway width and increase the stride length (Text-fig. 1B). If this assumption is confirmed, the timing and pattern of postural shift can be
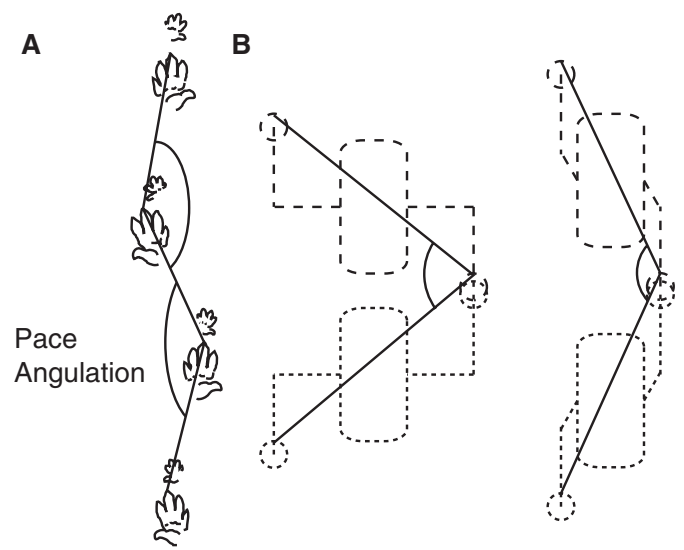

TEXT-FIG. 1. Measuring pace angulation and schematic diagram showing the ideal relationship between limb posture and pace angulation value. A, example of the measuring method illustrated from the Early Triassic archosaur trackway Chirotherium barthii (modified from Sickler 1836). B, left diagram represents a sprawler and right diagram represent a more erect form. An adducted limb of the erect form ideally narrows the trackway and extends the stride length, and as a consequence increases pace angulation value. traced from Permian and Triassic trackways, which are more abundant than skeletal fossils. So far, however, only isolated reports have been presented. For example, narrow trackways of therapsids suggesting semierect or erect posture have been noted from the Late Permian (Smith 1993; McKeever 1994).

Our aims in this paper are twofold. First, we assess whether pace angulation is an unequivocal indicator of sprawling or erect posture. Second, we measure pace angulation of a large sample of Permian and Triassic trackways to see how they changed through time, when the major shift occurred and which taxa manifest the shifts.

\section{MATERIALS AND METHODS}

We collected pace angulation data for hind feet from Permian, Triassic and modern animal trackways engaged in a symmetrical gait, namely walking and trotting, in which the trackway shows a zig-zag pattern (Text-fig. 1). Other trackway patterns left by asymmetrical gaits, such as galloping, were ignored. Although an asymmetrical gait has been observed in some modern tetrapods, known Permian and Triassic trackways do not show these gaits. Species of trackmaker are generally not diagnosable from trackways and it is hard to distinguish ontogenetic and interspecific differences (Farlow and Pianka 2000), so the analysis of fossilized trackways in the present study is based not on ichnospecies but on trackways.

Only one pace angulation value was taken from each published trackway. In most published accounts, it is not mentioned whether pace angulation was determined by connecting tips, rear ends or middle points of footprints. Mixing these values may cause some errors, but we could not standardize the method of measurement. When pace angulation values were not mentioned in the literature, we measured values directly from published figures and averaged them. The tip of the middle toe, or the midpoint between the tips of the two middle toes, for each successive footprint was connected to determine pace angulation (Text-fig. 1). For birds, the impressions of metatarsal phalangeal pads were connected, because it was often hard to determine the middle toe for some taxa. When several values for pace angulation are quoted from one trackway, the mean value was taken. If we measured several pace angulation values from one trackway, an average value was adopted.

We determined pace angulations from a wide range of modern mammals ( $\mathrm{n}=73,56$ species) and birds $(\mathrm{n}=83$, 69 species, 4 nonvolant) taken from published illustrations (Elbroch 2003; Elbroch et al. 2001; Table S1). Among those mammalian trackways, 17 were from 'cursorial' mammals and 11 were from 'noncursorial' mam- 
mals. These were compared with pace angulations for salamanders ( $\mathrm{n}=111,14$ species), lizards $(\mathrm{n}=56,14$ species), turtles ( $\mathrm{n}=5,5$ species) and a crocodile $(\mathrm{n}=1)$ also from the literature (Appendix S1). Locomotion speeds could be collected for only 37 trackways, all of which were made by lizards.

In a comprehensive survey, 461 individual published Permian and Triassic trackways were collected (Table S1). These trackways were grouped into five time categories: Early Permian $(\mathrm{n}=124)$, Late Permian $(\mathrm{n}=41)$, Early Triassic $(\mathrm{n}=141)$, Middle Triassic $(\mathrm{n}=88)$ and Late Triassic $(n=67)$. Ages of track-bearing geological formations were confirmed from current synopses of PermoTriassic stratigraphy (e.g. Smith 1993; Lucas 1998, 2007; Benton et al. 2004) and matched to the marine time scale (Gradstein et al. 2004). Note that grouping was simply to epoch level, not stage or substage, so age assignments are generally uncontroversial at that level of discrimination. No track records from the Middle Permian have been reported (Lucas 2007). Triassic trackways were assigned to major taxonomic categories, namely, archosauromorphs, therapsids and other taxa, based on inferences presented in the original papers: archosauromorphs were further divided into dinosauromorphs and others. There have been sufficient reviews of major Permo-Triassic track types that a strong consensus has emerged on broad taxonomic assignment of tracks, whether synapsid or diapsid, archosauromorph or dinosauromorph (Haubold 1971; Carrano and Wilson 2001; Demathieu and Demathieu 2004; Lucas 2007).

To test the effect of body size on pace angulation value, average foot length was noted from Permian and Triassic trackways when available: Early Permian $(\mathrm{n}=95)$, Late Permian $(\mathrm{n}=27)$, Early Triassic $(\mathrm{n}=112)$, Middle Triassic $(n=49)$ and Late Triassic $(n=61)$. We applied analysis of covariance (ANCOVA) with pace angulation as the dependent variable, age (Permian and Triassic) as the independent variable and log-transformed foot length (hereafter referred to as log (foot length) as the covariate.

Median and quartile values were calculated for each taxon and epoch. Pairwise Mann-Whitney $U$-tests were used to assess differences between time groups and taxa. Statistical analyses were conducted using the program ' $R$ ' (ver. 2.2.1) and JMP 6.3.0 (SAS Institute Inc., Cary, NC, USA).

\section{RESULTS}

Comparisons of pace angulation for all modern tracks show that only birds and mammals are not significantly different. The median value for mammals is 151.5 degrees and for birds 155.5 degrees $(\mathrm{p}=0.08)$. These two groups of 'erect' taxa differ from lizards, salamanders and turtles (median values were 110, 92 and 62 degrees, respectively), and these three 'sprawling' groups also differ significantly among themselves $(p<0.05)$. The pace angulation value of the high-walking crocodilian trackway was 113 degrees, which is between the values for 'erect' taxa and 'sprawling' taxa, but because of its small sample size, the crocodilians are not significantly different from any other groups ( $p>0.05)$. There is an obvious difference between the ranges of the two postural categories, erect and sprawling $(\mathrm{p}<0.01)$. The total ranges (Text-fig. $2 \mathrm{~A})$ overlap between 95 and 148 degrees, but the interquartile range for all sprawlers falls below 107 degrees, and that for all erect forms falls above 138 degrees. 'Cursorial' or 'fully erect' (felid and canid) and 'noncursorial' (didelphids, murids and mustelids) mammalian groups are also compared (Text-fig. 2A). As expected, the pace angulation of the noncursors is lower than that of the cursors (median values were 133 and 164 degrees, respectively); nonetheless, the interquartile range $(>120)$ and median values for the noncursorial mammals fall broadly above those for sprawlers.

The median values for Early and Late Permian, Early, Middle and Late Triassic trackway samples are $88,87.5$, 139.5, 149 and 156.5 degrees, respectively (Text-fig. 2B). Samples from the Permian epochs are indistinguishable from each other in the distributions of pace angulation $(\mathrm{p}=1.0)$, but significantly lower than all Triassic epochs $(\mathrm{p}<0.01)$. Comparisons among the Triassic divisions show that Early and Middle Triassic samples are indistinguishable from each other $(\mathrm{p}=1.0)$, Middle and Late, and Early and Late Triassic samples are significantly different $(p=0.0429$ and 0.0017$)$, because of the small percentage of low pace angulation trackways in the Late Triassic (Text-fig. 2B).

The median pace angulation values for archosauromorphs, therapsids and all other taxa of the Triassic are 158, 138 and 105 degrees, respectively (Textfig. 2C). These differ significantly from each other $(\mathrm{p}<0.01)$. Within Archosauromorpha, Dinosauromorpha and non-Dinosauromorpha have median values of 160.5 and 157 degrees and these do not differ significantly $(p=0.26)$. Comparisons of Early, Middle and Late Triassic archosauromorph assemblages (Text-fig. 2D) show median values of pace angulation of 156, 161.5 and 159 degrees, respectively. There are no significant differences between pairs of these three groups $(p>0.05)$ except between Early and Middle Triassic archosaurs $(\mathrm{p}=0.025)$.

The result of ANCOVA showed age, log (foot length) and interaction of the two values were statistically significant (Table 1; Text-fig. 3). This indicates that the adjusted mean of pace angulation is greater in the Triassic, and that regression slopes are significantly different between the two epochs. The regression slope for the Triassic was 


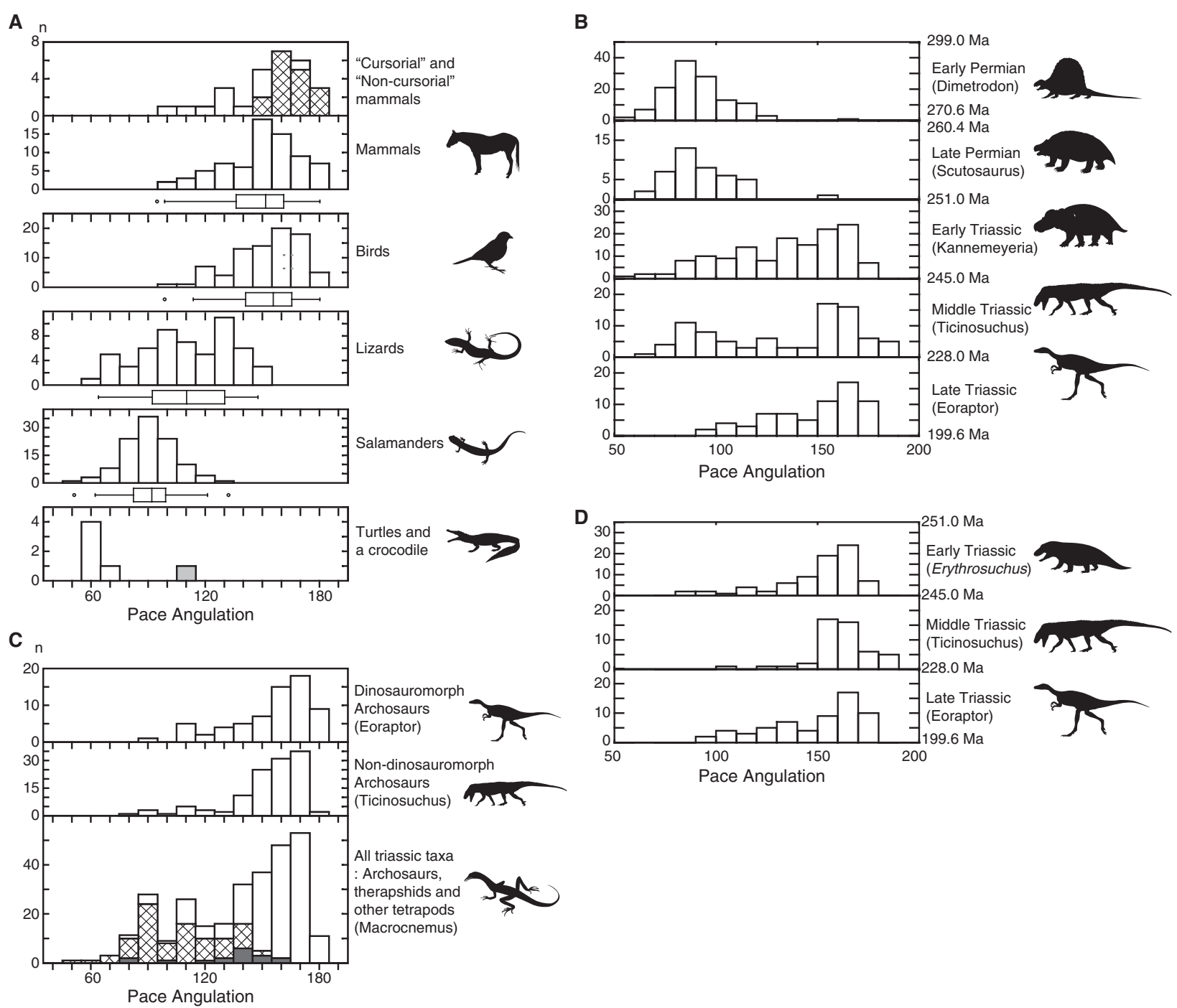

TEXT-FIG. 2. Pace angulation and posture. Histograms of pace angulation values of various modern tetrapods and the Permian and Triassic fossilized trackways. Higher pace angulation indicates more erect limb posture and lower pace angulation indicates more sprawling limb posture. Silhouettes show typical representatives of each category. Data are available as a Supplementary table. Absolute ages are based on Gradstein et al. (2004). A trackway with pace angulation higher than 180 degrees is not plotted. A, comparisons of modern tetrapods that belong to various limb posture categories; box plots are shown below the histograms of mammals, birds, lizards and salamanders. Note the distinction between sprawling and erect forms. In the highest histogram, the lattice columns indicate 'cursorial' mammals and the plain columns represent 'noncursorial' mammals. In the lowest histogram the grey column indicates the pace angulation value of the single crocodile sample. B, comparisons of trackways from different epochs in the Permian and Triassic show the major shift from sprawling to erect postures across the PermoTriassic boundary. Each histogram represents an epoch of the Permian and Triassic. Note the drastic shift to higher pace angulation from the Late Permian to the Early Triassic and emergence of trackways with high pace angulation ( $>150$ degrees) in the Early Triassic. C, comparisons of various Triassic taxa. The lower histogram shows the distribution of all Triassic tracks. The plain columns indicate archosauromorphs, the black columns represent therapsids and the lattice columns indicate other Triassic taxa. Archosauromorphs are exclusively dominated by high pace angulation trackways, therapsids show intermediate values, and other tetrapods show low pace angulation. Within Archosauromorpha, Dinosauromorpha in the upper histogram and non-Dinosauromorpha in the middle histogram are similar in the pace angulation distributions. D, comparisons among the Early, Middle and Late Triassic archosauromorphs show that the general patterns of these three epochs are similar, and that the trackways of archosauromorphs do not change significantly through the Triassic since they first emerged in the Early Triassic. 
TABLE 1. Result of ANCOVA, testing effects of age (Permian and Triassic), log-transformed foot length (a proxy of body size) and the interaction of the variables on pace angulation.

\begin{tabular}{llllll}
\hline & Estimate & SE & $t$ & $\mathrm{p}$ \\
\hline Intercept & 96.85 & 3.22 & 30.07 & $<0.001$ \\
Age (Triassic) & 11.68 & 3.22 & 3.63 & $<0.001$ \\
Log (foot length) & 9.35 & 1.52 & 6.16 & $<0.001$ \\
Age $\times \log$ (foot length) (Triassic) & 6.01 & 1.52 & 3.96 & $<0.001$ \\
\hline
\end{tabular}

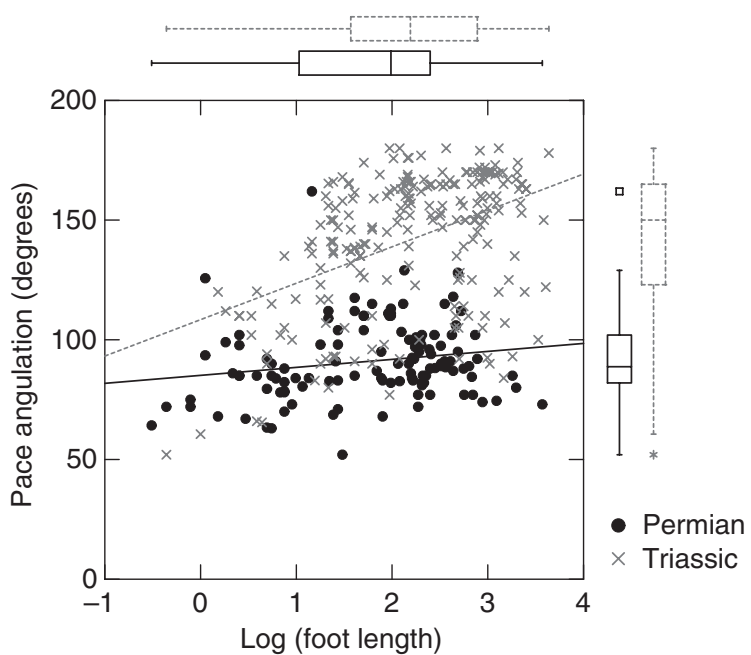

TEXT-FIG. 3. Pace angulation and foot length in Permian and Triassic trackways. From the scatter plot and box plots, it is obvious that foot length ranges of the Permian and Triassic overlap each other. On the other hand, except for four trackways, pace angulation values of all Permian trackways fall within the lower quartile range of Triassic trackways. Pace angulation is largely restricted by age regardless of foot length. Regression lines show there is a positive correlation between foot length and pace angulation value in the Triassic but not in the Permian. These demonstrate that only pace angulation, but not foot length, changed between the Late Permian and Early Triassic. One point with a pace angulation larger than 180 degrees is not plotted. Box plot and regression line for the Permian are shown by solid lines and these for Triassic are shown by dotted lines.

15.36, whereas that for Permian was 3.33 and was not significantly different from $0(t=1.40, \mathrm{p}=0.16)$.

\section{DETERMINANTS OF PACE ANGULATION}

Could we be documenting merely a change in speed or body size across the Permo-Triassic boundary (PTB)? The question is whether posture may be determined from footprints irrespective of these factors. Unfortunately, most data on modern trackways are not provided with full information on speed and body size, and this makes it hard to assess the influence of these factors rigorously. Nonetheless, it seems that speed and body size cannot explain our data.

Evidence from modern tracks suggests that pace angulation values of the fastest-moving sprawlers do not overlap the pace angulation values of slow-moving erect animals. Speed of movement affects pace angulation. As an animal moves faster, the stride length increases, and so does the pace angulation. Comparisons of pace angulation among modern animals with known locomotion speed are insightful. Speed is known from only 37 trackways of seven lizard species (Sukhanov 1968). Walking cursorial mammals are not very fast compared to these lizards. For example, the walking speed is between 1.6 and $5 \mathrm{~km} / \mathrm{h}$ for cats, dogs and foxes (Jenkins and Camazine 1977). Sixteen tracks were made by lizards moving at $5-13 \mathrm{~km} / \mathrm{h}$, and the pace angulations ranged from 114 to 148 degrees, with an average of 134 degrees. Considering their small size, relative speeds of these lizards are much faster than those of cursorial mammals, but the pace angulations of lizards with faster speeds do not overlap those of walking cursorial mammals ( $>151$ degrees). Although speed correlates strongly with pace angulation within the same postural category (the correlation between speed and pace angulation in the lizards is high $r=0.80$ ), it is probable that limb posture is still more influential on pace angulation than speed in broader comparisons.

Body size could be an important factor in determining pace angulation, as limb postures of modern tetrapods largely correlate with their body mass. Most modern sprawlers, namely lizards, salamanders and newts, are small. In contrast, mammals and birds, modern erect forms are relatively large. Moreover among mammals, larger 'cursorial' taxa tend to possess fully erect limbs (Jenkins and Camazine 1977; Stein and Casinos 1997), whereas smaller mammals show relatively sprawling limb posture (Jenkins 1971; Biewener 1989). Thus the shift in pace angulation value could simply reflect a shift in body size. This was assessed for the Permo-Triassic track data by checking the foot length $(n=346)$. Ranges of foot lengths of the Permian $(0.6-35.5 \mathrm{~cm})$ and Triassic $(0.7-$ $38 \mathrm{~cm}$ ) samples substantially overlap each other. Median foot lengths of all sampled Permian and Triassic trackways are 7.2 and $8.9 \mathrm{~cm}$, respectively, so more or less the same. In contrast, except for four trackways, pace angulations of all Permian trackways fall below the lower quartile range of Triassic trackways (Text-fig. 3). Nevertheless, all Permian footprints were made by animals with plantigrade feet, whereas Triassic footprints include those produced by both plantigrade and digitigrade animals, the latter primarily dinosauromorphs. Dinosauromorph trackways did not occur in the Early Triassic, so the effect of foot posture can be eliminated by comparing Late 
Permian and Early Triassic trackways. Median foot length is 5.5 and $5.6 \mathrm{~cm}$ for the Late Permian and Early Triassic, whereas the median pace angulation value is 85 and 143.5 degrees.

The result of the ANCOVA showed that the effects of both age and log (foot length) are highly significant (Table 1). However, the effect of foot length on pace angulation significantly differs between geological ages. Although there was a significant positive correlation observed for the Triassic, the regression slope for the Permian was not significantly different from 0 (Textfig. 3). Body size did not affect limb posture in the Permian as relatively large animals also seemed to be sprawlers. The aforementioned relationship between body size and limb posture seen today might have started in the Triassic. These results demonstrate the shift in pace angulation across PTB was not correlated with changes in body size.

These considerations show that, although speed can be influential in determining pace angulation among animals with similar posture, limb posture is the key factor in determining pace angulation, especially on the large scale shown here. Body size is likely to correlate with pace angulation as it is a determinant of limb posture in modern animals. Nevertheless, when considering Permian tetrapods, this relationship cannot be applied.

Limb posture is generally represented by the angle of the femur, but movement of the crus and pelvis and the proportion of these limb segments and pelvis also affect pace angulation value. Pelvic rotation, in other words body undulation, increases pace angulation values (Smith 1993). It is known that more erect animals tend to have less pelvic rotation (Reilly and Elias 1998). Therefore, pelvic rotation is likely to weaken the influence of limb posture on pace angulation value, as it usually increases the pace angulation value of sprawlers. The close pace angulation value of high-walking crocodilians (semierect) and lizards (sprawling) may be explained by the influence of pelvic rotation and the inclusion of many fast-moving lizards in the data set. Distal limb segments tend to adduct more than proximal segments, consequently contributing less to the trackway width and more to the stride length. Thus, if all limb joints make the same movement, a higher pace angulation value is likely to be produced by the body in proportion to the longer distal segments. This may explain why the pace angulation of lizards is higher than that of salamanders, which have relatively short limbs. Pelvic rotation in Triassic tetrapods probably rather decreased through time as the number of sacral vertebrae increases in archosaurian lineages and synapsid lineages. No radical change in limb proportions was reported from skeletal data on Early Triassic tetrapods. Therefore these two factors are unlikely to be causes of the shift in pace angulation across PTB.

\section{POSTURAL CHANGE ACROSS THE PERMO-TRIASSIC BOUNDARY}

There is a major shift in pace angulation values across the PTB (Text-fig. 2B) when median values jump from 87.5 (Late Permian) to 139.5 degrees (Early Triassic). Only two out of more than one hundred Permian trackways have pace angulation values higher than 130 degrees, whereas pace angulations of more than 60 per cent of Early Triassic trackways exceed 130 degrees. During the Triassic, the ratio of low pace angulation trackways decreases (Text-fig. 2B), and as a result the median values of pace angulation gradually increase from 139.5 (Early Triassic) to 156.5 degrees (Late Triassic). From skeletal studies, it is known that Late Permian tetrapods were largely sprawlers, and the Late Triassic fauna was dominated by dinosaurs, obligatorily erect forms, and so there must have been a postural transition from sprawling to erect between those times. Nevertheless, the reptilian body fossil record is sparse in the Early and Middle Triassic; for example, there is only a limited archosaurian record in the early Middle Triassic (Sereno 1991). Consequently, the pattern of postural shift (i.e. gradual or rapid) remained obscure. Considering the trackway record presented in this study, it is most reasonable to assume that the postural shift occurred primarily between the Late Permian and Early Triassic.

The postural shift documented in this study between the Late Permian and Early Triassic happened during the 15 myr of the Late Permian (9 myr) and Early Triassic (6 myr) (Gradstein et al. 2004). The Early and Late Permian track faunas show almost no definitely erect forms, while most, but not all, Early Triassic forms fall in the convincingly erect range (Text-fig. 2B). So, an erect posture apparently swept through terrestrial tetrapod faunas during the 15 myr of the Late Permian and Early Triassic. This is much earlier than indicated by previous studies of locomotory evolution based on skeletal fossils (Charig 1972; Kemp 1982; Bonaparte 1984; Parrish 1987), which suggested that the transition finished some 1520 myr after the PTB, towards the end of the Middle Triassic. Further, studies of tetrapod recovery from the PTB event (Benton 1983; Benton et al. 2004; Sahney and Benton 2008) suggest that tetrapod ecosystems did not recover pre-extinction diversity and complexity until that same point, some 15-20 myr after the event. The impact of the postural shift could be exaggerated, if erect organisms left more trackways than sprawlers. Nevertheless, similarities of pace angulation values among the Triassic epochs indicate that the radiation of erect organisms was nearly completed during the Early Triassic, especially among archosaurs, as shown below.

Tracks are notoriously hard to match with their exact producers (Farlow and Pianka 2000; Carrano and Wilson 
2001), but there is some consensus on the assignment of the Permian and Triassic footprints to broad taxonomic groups, based on morphologies of digits, hands and feet and comparisons of tracks with hand and foot skeletons (Haubold 1971; Demathieu and Demathieu 2004). Considering that the Triassic tracks are morphologically more diverse than the Permian tracks (Demathieu and Demathieu 2004), it is important to attempt to identify which major tetrapod groups were primarily responsible for the rapid increase in pace angulation, although the following section should be treated with some caution as it relies on identification of trackmakers. The identifications are not ours, but those indicated in cited publications.

In the database, each measured Triassic track was assigned to the broad taxonomic group of the presumed maker: archosaur, therapsid or other tetrapod group. The archosaur tracks were further subdivided into those made by presumed dinosauromorphs and non-dinosauromorphs. Assumed non-dinosauromorph archosaurian trackways mostly (95\%) consist of the 'crocodiloid' group of Demathieu and Demathieu (2004), namely Chirotherium, Isochirotherium, Brachychirotherium, Sphingopus and Synaptichnium. This group is characterized by the orientation of the fifth digit, which lies behind and separated from the other four. Dinosauromorph trackways include ichnogenera such as Coelurosaurichnus, Evazoum, Grallator, Gregaripus, Agrestipus, Otozoum and Anchisauripus. Most of these are diagnostic as they are tridactyl. Dicynodontipus, Therapsipus and two unnamed trackways of Marsicano and Barredo (2004) are regarded as therapsid trackways. These footprints show a rounded sole pad, and the shape and size of manus and pes are similar to each other. For other minor ichnotaxa and unnamed trackways, the trackmaker assumptions of the original papers from which data were taken, were followed.

It is clear that archosaurs, and to a lesser extent, therapsids, were responsible for the high pace angulation of Triassic trackways (Text-fig. 2C). The 'other tetrapods' category, including footprints made by amphibians, procolophonids and 'lacertoids' (superficially lizard-like tracks made perhaps by small basal diapsids) are, as expected, quite distinct and clearly in the sprawling category. In further detail, the fact that the pace angulations of dinosauromorph and non-dinosauromorph archosaurs were not significantly different implies that the range of limb postures seen among the Triassic dinosauromorphs was about the same as for other Triassic archosaurs. Dinosauromorphs have always been ascribed an erect posture in osteological studies, but it was less clear that crocodile-line archosaurs, such as aetosaurs, rauisuchians and crocodilomorphs were also largely erect. The current study confirms previous osteological studies (Bonaparte
1984; Parrish 1987), and is a useful reminder that dinosauromorphs were not unique in the evolution of erect posture.

The aforementioned abrupt shift in reptilian posture at the PTB was mostly caused by the emergence and radical increase in the number of archosaurian trackways in the Early Triassic. Although known Early Triassic archosaurs, for instance proterosuchids and erythrosuchids, are considered as sprawlers, more derived erect-limbed archosaurian taxa may have already existed in the Early Triassic as indicated by fragmentary materials from Russia (Gower and Sennikov 2000) and by ghost ranges established from cladograms (Sereno 1991; Benton 1999). The consequent gradual increase in mean pace angulation values during the Triassic was probably because of the increasing proportions of archosaurian trackways, from 55 and 56 per cent in the Early and Middle Triassic to 91 per cent in the Late Triassic, in our data.

There are sufficient archosaurian trackways from the Triassic that comparisons can be made among the Early, Middle and Late Triassic assemblages (Text-fig. 2D). The median values of pace angulation for these assemblages are between that of modern cursorial mammals (164 degrees) and those of all mammals or birds (151.5 and 155.5 degrees), and do not show much difference among the three time groups (Text-fig. 2D). The pace angulation of the earliest known archosaurian trackways (Dienerian; early Early Triassic) is already high compared to the Permian trackways (Ptaszynski 2000). Considering this evidence, an erect posture probably evolved during the Early Triassic in archosaurs and remained unchanged during the Triassic through the emergence of dinosaurs in the Late Triassic.

Permo-Triassic therapsid trackway data are scarce, and not enough for a statistical analysis. However, a few Permian trackways attributed to therapsids have pace angulations about 150 degrees (Smith 1993; McKeever 1994), which are unlikely to have been made by sprawlers. The late Early Triassic, namely Olenekian, therapsid trackways (Haubold 1971) also showed an erect or semierect limb posture, with pace angulation values up to 158 degrees.

\section{CONCLUSIONS}

The trace fossil record is clearly a rich source of data on the evolution of the posture of extinct organisms (Wilson 2005). Trace fossils have been characterised as fossilised behaviour, and indeed what evidence of a particular episode of walking or running $250 \mathrm{myr}$ ago could be more graphic than a trackway? An analysis of compiled fossil trackway data potentially extends our knowledge about the evolution of tetrapod locomotion. We have shown 
that erect posture was presaged in some therapsid lineages in the Late Permian and was inherited by their Early Triassic descendants. Moreover, archosaurs with erect posture emerged and increased radically in the Early Triassic, within the first 6 myr of recovery from the profound PTB mass extinction. This is considerably faster than the 1520 myr suggested by the study of skeletal fossils, and the establishment of erect-postured faunas was considerably earlier than the wholesale rebuilding of Triassic tetrapod ecosystems (Benton et al. 2004).

Acknowledgements. TK thanks M. Manabe for valuable discussions and providing literature, M. Elbrock and J. O. Farlow for information about modern trackways, S. J. Braddy and S. Fujiwara for drawing attention to footprints, R. Werneburg for hospitality at the Museum Schleusingen, members of the Ueno Zoo Vivalium for access to modern reptiles, M. Ozaki for discussions, critical review of the manuscript, advising statistics and allowing access to JMP, K. Tanabe, T. Oji, all members of the palaeontological seminar of the University of Tokyo, M. Sakamoto for discussions and critical review of the draft. We also thank K. Padian, C. Sullivan, and other reviewers of the manuscript for their helpful suggestions. TK acknowledges his family and Government of Canada Post-Doctoral Research Fellowship Program for financial support. MJB acknowledges grant support from NERC, the Royal Society, and the National Geographic Society.

\section{SUPPORTING INFORMATION}

Additional Supporting Information may be found in the online version of this article:

Table S1. Trackway data used in the analysis.

Appendix S1. References for the supplementary table.

Please note: Wiley-Blackwell are not responsible for the content or functionality of any supporting materials supplied by the authors. Any queries (other than missing material) should be directed to the corresponding author for the article.

\section{REFERENCES}

BENTON, M. J. 1983. Dinosaur success in the Triassic: a noncompetitive ecological model. Quarterly Review of Biology, 58, 29-51.

- 1999. Scleromochlus taylori and the origin of dinosaur and pterosaurs. Philosophical Transactions of the Royal Society of London, Series B, 354, 1423-1446.

— TVERdokHlebov, V. P. and SURKOV, M. V. 2004. Ecosystem remodelling ong vertebrates at the PermianTriassic boundary in Russia. Nature, 432, 97-100.

BIEWENER, A. A. 1989. Scaling body support in mammals: limb posture and muscle mechanics. Science, 245, 45-48.

BLOB, R. W. 2000. Interspecific scaling of the hindlimb skeleton in lizards, crocodilians, felids and canids: does limb bone shape correlate with limb posture? Journal of Zoology, London, 250, 507-531.

— 2001. Evolution of hindlimb posture in non-mammalian therapsids: biomechanical tests of paleontological hypotheses. Paleobiology, 27, 14-38.

BONAPARTE, J. F. 1984. Locomotion in rauisuchid thecodonts. Journal of Vertebrate Paleontology, 3, 210-218.

CARrano, M. T. and WILSON, J. A. 2001. Taxon distributions and the tetrapod track record. Paleobiology, 27, 564-582.

CARRIER, D. R. 1987. The evolution of locomotor stamina in tetrapods - circumventing a mechanical constraint. Paleobiology, 13, 326-341.

CHARIG, A. J. 1972. The evolution of the archosaur pelvis and hindlimb: an explanation in functional terms. 121-151. In JOYSEY, K. A. and KEMP, T. S. (eds). Studies in vertebrate evolution. Oliver and Boyd, Edinburgh, $284 \mathrm{pp}$.

DemAThiEU, G. and DEMATHIEU, P. 2004. Chirotheria and other ichnotaxa of the European Triassic. Ichnos, 11, 7988.

ELBROCH, M. 2003. Mammal tracks and sign: a guide to North American species. Stackpole Books, Mechanicsburg, 779 pp.

-MARKS, E. and BORETOS, C. D. 2001. Bird tracks and sign: a guide to North American species. Stackpole Books, Mechanicsburg, $456 \mathrm{pp}$.

FARLOW, J. O. and PIANKA, E. R. 2000. Body form and trackway pattern in Australian desert monitors (Squamata, Varanidae); comparing zoological and ichnological diversity. Palaios, 15, 235-247.

GATESY, S. M. 1991. Hind limb movements of the American alligator (Alligator mississippiensis) and postual grades. Journal of Zoology, London, 224, 577-588.

GOWER, D. J. and SENNIKOV, A. G. 2000. Early archosaurs from Russia, 140-159. In BENTON, M. J., SHISHKIN, M. A., UNWIN, D. M. and KUROCHKIN, E. N. (eds). The age of Dinosaurs in Russia and Mongolia. Cambridge University Press, New York, 696 pp.

GRADSTEIN, F. M., OGG, J. G., SMITH, A. G., et al. (37 others) 2004. A geologic time scale 2004. Cambridge University Press, Cambridge, 589 pp.

HAUBOLD, H. 1971. Ichnia amphibiorum et reptiliorum fossilium. Handbuch der Paläoherpetologie, Vol. 18. Gustav Fischer, Stuttgart, $184 \mathrm{pp}$.

HUTCHINSON, J. R. 2006. The evolution of locomotion in archosaurs. Comptes Rendus Palévol, 5, 519-530.

JAYNE, B. C. and IRSCHICK, D. J. 1999. Effects of incline and speed on the three-dimensional hindlimb kinematics of a generalized iguanian lizard (Dipsosaurus dorsalis). Journal of Experimental Biology, 202, 43-159.

JENKINS, F. A. 1971. Limb posture and locomotion in the Virginia oppossum (Didelphis marsupialis) and in other non-cursorial mammals. Journal of Zoology, London, 165, 303315 .

— and CAMAZINE, S. M. 1977. Hip structure and locomotion in ambulatory and cursorial carnivores. Journal of Zoology, London, 181, 351-370.

KEMP, T. S. 1982. Mammal-like reptiles and the origin of mammals. Academic Press, London, 363 pp. 
LUCAS, S. G. 1998. Global Triassic tetrapod biostratigraphy and biochronology. Palaeogeography, Palaeoclimatology, Palaeoecology, 143, 347-384.

2007. Tetrapod footprint biostratigraphy and biochronology. Ichnos, 14, 5-38.

McKEEVER, P. J. 1994. The behavioral and biostratigraphical significance and origin of vertebrate trackways from the Permian of Scotland. Palaios, 9, 477-487.

PARRISH, J. M. 1987. The origin of crocodilian locomotion. Paleobiology, 13, 396-414.

PEABODY, F. E. 1959. Trackways of living and fossil salamanders. University of California Publication in Zoology, 63, $1-72$.

PTASZYNSKI, T. 2000. Lower Triassic vertebrate footprints from Wióry Holy Cross Mountains, Poland. Acta Paleontologica Polonica, 45, 151-194.

RAY, S. and CHINSAMY, A. 2003. Functional aspects of the postcranial anatomy of the Permian dicynodont Diictodon and their ecological implications. Palaeontology, 46, 151183.

REILLY, S. M. and ELIAS, J. A. 1998. Locomotion in Alligator mississippiensis: Kinematic effects of speed and posture and their relevance to the sprawling-to-erect paradigm. Journal of Experimental Biology, 201, 2559-2574.

SAHNEY, S. and BENTON, M. J. 2008. Recovery from the most profound mass extinction of all time. Proceedings of the
Royal Society of London. Series B, Biological Sciences, 275, 759765. doi: 10.1098/rspb.2007.1370.

SERENO, P. C. 1991. Basal archosaurs: phylogenetic relationship and functional implications. Journal of Vertebrate Paleontology, 11, 1-53.

SICKLER, F. 1836. [Foreword to] Kessler, G. Die vorzüglichsten Fährten-Abdrücke urweltlicher Thiere in bunten Sandstein, aus den Sandsteinbruchen der Umgegend von Hildburghausen. Kesselringsche Hofbuchhandlungen, Hildburghausen, 8 pp.

SMITH, R. M. H. 1993. Sedimentology and ichnology of floodplain paleosurfaces in the Beaufort Group (Late Permian), Karoo Sequence, South Africa. Palaios, 8, 339-357.

SPEZZANO, L. C. Jr and JAYNE, B. C. 2004. The effects of surface diameter and incline on the hindlimb kinematics of an arboreal lizard (Anolis sagrei). Journal of Experimental Biology, 207, 2115-2131.

STEIN, B. R. and CASINOS, A. 1997. What is a cursorial mammal? Journal of Zoology, London, 242, 185-192.

SUKHANOV, V. B. 1968. General system of symmetrical locomotion of terrestrial vertebrates and some features of movement of Lower Tetrapods. The Amerind Publishing Co., New Delhi, $274 \mathrm{pp}$.

WILSON, J. A. 2005. Integrating ichnofossil and body fossil records to estimate locomotor posture and spatiotemporal distribution of early sauropod dinosaurs; a stratocladistic approach. Paleobiology, 31, 400-423. 